\title{
The Use of Indigenous Games to Enhance the Learning of Word Problems in Grade 4 Mathematics: A Case of Kgati
}

\author{
Tshele J. Moloi \\ North West University -Potchefstroom Campus \\ https://orcid.org/0000-0002-3533-2852 \\ Moeketsi S. Mosia \\ Sol Plaatje University, South Africa \\ https://orcid.org/0000-0002-7189-0018 \\ Mogalatjane E. Matabane \\ Sol Plaatje University, South Africa \\ https:// orcid.org/0000-0001-7953-6729 \\ Khanyane T. Sibaya \\ Mafika-Ditshiu Primary School \\ https:// orcid.org/0000-0003-0882-2925
}

\begin{abstract}
This paper explores the value of indigenous games in the teaching and learning of word problems in Grade 4 mathematics. In particular, the paper explains how the moves of *kgati (skipping rope) can be used to enhance the teaching and learning of mathematics word problems. Participatory action research (PAR) methodology was used to generate data so as to enable participants to work collaboratively, freely and with confidence. Participants of this study were Grade 4 learners, a head of department, two Grade 4 mathematics teachers, a life skills teacher, a mathematics subject advisor, four parents and three members of the local royal family. The study seeks to answer the question: To what extent can learners use knowledge of the kgati (skipping rope) game to enhance the learning of mathematics word problems? Community cultural wealth (CCW) theory was employed as a lens that acknowledges the huge wealth of knowledge that participants bring from their homes into the classroom. These forms of capitals include aspirational, navigational, social, linguistic, familial and resistant capital which relate to the knowledge learners bring from home and use to tap into word problems. Critical discourse analysis was used to analyse the words of the research team to reach their deeper meanings. The results of the study indicate that learners can interpret, convert and link their indigenous knowledge with mathematics and improve their understanding of mathematics concepts when indigenous knowledge is
\end{abstract}


incorporated. Incorporating kgati moves to learn word problems significantly improved learners' creativity and imagination. The study further suggests that learners work better when given opportunities for interactive and collaborative activities that relate to their daily practices.

Keywords: the moves of *kgati, mathematics word problems; community cultural wealth; indigenous knowledge; Eurocentric

\section{Introduction}

Over the past decade, critical scholars have led a paradigm shift in mathematics that seeks to challenge the deficit discourse, the privileged perspective of mathematics, the marginalisation of indigenous knowledge and the mistreatment of black students in mathematics education classrooms, research and society (Wright, 2018; Osibodu, 2020; Moloi, 2013). Learners in the elementary grades (Grades R- 6) learn mathematics word problems more easily and with better understanding when the teaching draws from lived experiences and cultural practices, including indigenous games such as kgati (Chapman, 2006; Rubel, 2017; Hunter \& Hunter, 2018). This is affirmed by Nkopodi and Mosimege (2009) who cite morabaraba (board game) and diketo (coordination game) as examples of indigenous games that could assist learners to learn mathematics word problems better and with deeper understanding. In support of this view, Dziva, Mpofu and Kusure (2011) state that using indigenous games to teach mathematics gives learners the opportunity to learn how to link their everyday experiences with mathematics. Cognisant of the foregoing, the researchers confirm that children learn mathematical word problems optimally when their learning is deep-rooted in playful activities, thus using play to learn (Imray \& Hinchcliffe, 2013; Young \& Murray, 2017; Moro, 2020).

Considering the above, in this study learners were given platforms to translate the knowledge gained from playing the indigenous game kgati into mathematics content and solving word problems. In the context of this paper, the moves of kgati refer to the way learners swing kgati (refer to Figure I) so that it forms two semicircles, the one facing upwards $\cup$, and the other facing downwards $\cap$. Community cultural wealth (CCW) was used as a lens to determine the extent to which the indigenous skills of learners can be used in learning mathematics word problems (Bishop, 1988; Vongai \& Elaosi, 2017). The CCW theory suggests "cultural knowledge, skills, abilities and contacts possessed by socially marginalized groups often go unrecognized and unacknowledged" (Yosso, 2005, p. 69). Participatory action research (PAR) was used as research methodology to generate data and to explore how learners, teachers and other relevant stakeholders could work together and connect indigenous games with the teaching of mathematics word problems. Critical discourse analysis was used as a tool to analyse the texts, spoken words and actions demonstrated by research participants to gain a deeper understanding of their meanings (Filmer, 2015; Van Dijk, 2004). Findings of the study are informed by the literature review and the discussions that relate to observing the moves of kgati. 


\section{Background and Literature}

This study contests the Eurocentric approach to learning mathematics. The phrase 'Eurocentric approach' refers to a view that the European culture is preeminent compared to other world cultures, including the African culture (Conrad, 2019; Williams, 2019). The Eurocentric view of mathematics rests on the foundation that Europeans created mathematics and posses superior intellectual ability. As a consequence, this study agrees with Davis $(2018$, p. 21) that it "misinforms blacks students about their people's place in the history of mathematics and seek[s] to destroy their racial and mathematics identities". According to this view, colonised Africans were regarded as empty vessels who could only sustain their livelihood through Western cultural systems and scientific knowledge (Odora Hoppers, 2002; Shonhai, 2016). The European thinking led colonised Africans to believe that their indigenous skills, knowledge and games could only be useful if they were presented as sports, play for enjoyment or fun and physical education to achieve fitness, but not in mathematics (Department of Sport \& Recreation, 2017; Dziva et al. 2011). The view also disseminated the idea that colonised Africans could only build their ambitions and futures through modern urban life, not in rural communities where indigenous knowledge is valued and African indigenous games, skills, knowledge and languages are dominant (Kaya \& Seleti, 2013; Riffel, 2020). This claim is affirmed by Shizha and Emeagwali (2016) who explain that most oppressed Africans studied through a system that schooled them to view and value African indigenous skills, knowledge and games as irrelevant in a formal system system.

According to Da Silva (FAO, 2015), learners that live in rural areas use the wealth of their cultural and indigenous knowledge to understand the world around them. Lucero (2010) indicates that this wealth of knowledge that sustains the learners is often marginalised in the teaching and learning of mathematics, particularly relating to mathematics word problems. However, Vongai and Elaosi (2017) state that the task-given instructions by teachers should be seen to link mathematics content with cultural knowledge. The Mathematics Curriculum Assessment Policy Statement (CAPS) defines mathematics as a human activity that aims to build relations between physical and social phenomena, and between mathematical objects themselves (Department of Basic Education, 2014). Thus, this definition creates a platform for rural learners' ways of knowing and learning mathematics word problems to be grounded in their social and physical contexts.

According to Matusov and Marjanovic-Shane (2017), "The modern way, which may soon be upon us, is to let students define what is mathematics means to them or their culture, and to work towards the goal of equality, that happy state when all are satisfied with their level of (self-defined) mathematical understanding". To this end, the teaching of mathematics which is imbued with learners' ways of being makes the learning of mathematics word problems to be an exciting and adventurous endeavour of human life. To buttress the foregoing, researchers (Maferetlhane, 2012; Moloi 2015; Vongai \& Elaosi, 2017) argue that in decolonising the Western education system, learners could use their social capital and cultural heritage in learning mathematics word sums. This argument is acknowledged by Long and 
Dunne (2014) and Knight (2003), suggesting that incorporating indigenous games into the teaching and learning of mathematics is significant because learners in elementary grades learn through playing. In acknowledging the importance of decolonisation in mathematics education, Nkopodi and Mosimege (2009) incorporated morabaraba, an indigenous game, in the learning of mathematics, and presented information on relevant skills and indigenous knowledge that could be linked with the game; however, they did not incorporate the moves of kgati in their paper. Therefore, using participatory action research, this paper investigated how the moves of kgati could enhance the teaching and learning of mathematics word problems.

\section{Problem Statement}

According to Moloi (2013), one of the reasons for poor performance in mathematics problem solving is the exclusion and marginalisation of the wealth of knowledge learners bring to the classroom. In the same breath, Moloi (2015) and Nabie (2015) posit that mathematics concepts are rooted in indigenous games and human beings have multiple realities of connections with their evironmental settings. This view is also shared by Sepeng (2015) and Knight (2003) when they argue that the mathematics curriculum that is divorced from learners' lived experience and badly written textbooks are some of the causes of learners' inability to interpret, convert and link the indigenous games (such as kgati) to word problems. Kavalo (2014) declares that the use of indigenous games to teach mathematics is original and unique, and if utilised within a particular culture and society, would yield great results. This argument links well with epistemological and ontological stances of ethnomathematics in the sense that mathematics acquaintance and realities are co-produced or made meaningful through the interaction between various parties (such as learners and parents) and not limited to teachers. Learners learn word problems when their backgrounds and experiences are considered. Again, ethnomathematics as a research programme is less of a complement to mathematics than a critique of the knowledge that is valorised as being mathematical knowledge. The prefix 'ethno-' shifts mathematics from places where it has been erected and glorified (schools and universities) and spreads it to the world of people, in their diverse cultures and everyday activities.

Thus, ethnomathematics brought to the mathematics education field new and refreshing insights, not just about the local or ethnic mathematics knowledge, but also in terms of historical, philosophical and political approaches involved in mathematics and its education. Weldeana (2016) contends that ethnomathematics is the way different cultural groups mathematise, that is, different communities can count, measure, relate, sort, compare, infer, hypothesise, problem pose, generalise, communicate, data gather and process, predict, analyse, record, evaluate, verify, and construct. Mathematising is understood as the way marginalised cultural groups use mathematical tools located in the context of their real-life situations to survive (Rosa \& Orey, 2016). In the context of this study, learners can mathematise because they are able to use and unearth mathematical content embedded within kgati. In addition, it can be pointed out that ethnomathematics as a human activity does not subscribe to 
the notion of the Platonist view. Platonists define mathematics as a static discipline which views mathematics as out there waiting to be discovered, where the work of mathematicians resembles a textbook, with no emotions and no signs of human authorship (Gail, 2002).

The Curriculum Assessment Policy Statement (CAPS) suggests that it is important to use learners' lived experience to make mathematics relevant and interesting. However, there is lack of research on the use of indigenous games to improve the teaching of word problems in mathematics. While Nkopodi and Mosimege (2009) incorporated morabaraba, an indigenous game, in the learning of mathematics, the use of $k g a t i$ has not been explored.

\section{Framework or Lens}

This study used the community cultural wealth (CCW) theory as a framework to examine the extent to which learners could use knowledge of the indigenous game kgati to enhance the learning of mathematics word problems. Yosso (2005) describes $\mathrm{CCW}$ as a theory that addresses the racial and social imbalances between people of the same society or group. Thus, CCW theory offers alternatives to the cultural deficit perspective and serves to "challenge the social injustice that Yosso believes is endemic in schools "(Yosso, 2005, p.12). As argued by Vega (2014: 10), CCW guides teachers to "acknowledge the strength of culturally related attributes, such as bilingual homes and large extended families, instead of seeing those qualities as barriers to success". By looking through the CCW lens, this study focuses on various forms of capitals, such as aspirational, navigational, social, linguistic, familial, and resistant, which acknowledge the knowledge that learners bring from their homes into the classroom setting. The teaching of word problems tapped into this capital wealth of knowledge which school learners bring from their marginalised communities. Considering aspirational wealth, it entails learners who are determined to master the word problems irrespective of the challenges they are facing. This capital suggests that learners come to school being motivated and eager to learn word problems and not being coerced. Therefore, it is expected of the mathematics teachers to tap in all these capitals and present word problems in interesting ways.

Navigational capital refers to learners who can maneuver, using various skills to solve word problems. This capital enhances the teaching and learning of word problems. Teachers do not have to take more time to explain ways of solving the word problems as learners already possess this capital. Rather, learners are allowed to discover these ways of learning word problems on their own. On the other hand, social wealth capital allows learners to interact in small groups to learn word problems. By its nature, social capital is manifested when learners network and interact freely in the daily life activities, such as the playing of kgati. Again, learners express themselves freely in their home languages to describe mathematical concepts with the same ease as they play kgati. This is made possible by the linguistic capital, which embraces intellectual skills and experiences learned at home, multiple language abilities and communication skills. These skills are often used in their daily life activities, for instance, when they play kgati. Furthermore, familial wealth is seen as the cultural knowledge 
developed through interactions with families and friends in sports and social community settings. This mutual interaction by learners is necessary in the fruitful learning of word problems. Lastly, it can be noted that resistant capital enables learners to challenge instances of inequity, unfairness, discrimination, oppression, and marginalisation instituted against them. This capital empowers learners to be alert to the fact that their interpretations and views on word problems should not be suppressed by teachers. Rather their voices and experiences need to be valued in the learning of word problems.

Thus, in the context of this paper, social capital was adopted to show how people networked with other people when observing and identifying mathematical shapes from the moves of kgati. Xenofontos and Papadopoulos (2015) encourage mathematics teachers to acknowledge the teaching of mathematics word sums with activities that will address cultural biases amongst the learners. To buttress the foregoing, Arenas, Reyes and Wyman (2017) argue the use of indigenous knowledge as being powerful and key in acquiring deeper mathematical knowledge.

The CCW theory fits well with the study since it involves parents, teachers and members of the royal family working together with learners, exploring the cultural capital and its relevance to mathematics learning. Lynn (2004) and Yosso (2002; 2005) argue that community cultural wealth acknowledges the cultural knowledges, skills and abilities possessed by learners. In this study, the use of an indigenous game, kgati, in teaching word problem skills in grade 4 mathematics classes is a way of recognising and acknowledging learners' cultural practices. In addition, Williams (2017) and Ernest (2010) contend that involving parents in the study of mathematics word sums is significant because it helps learners to perform better in the subject. More importantly, learners are excited at seeing parents and teachers working together to connect mathematics lessons taught at school with what learners and parents know and do at home.

\section{Conceptual Framework Guiding the Study}

The paper adopted ethnomathematics as the conceptual framework in enhancing the teaching and learning of word problems. According to Mukhopadhyay (2013), ethnomathematics is an instructional approach integrating significant cultural mathematics artefacts into the learning of mathematics. It provides learners with the opportunities to make sense of the mathematical concepts using personal experiences and cultural wealth. For instance, the moves of kgati are rich in mathematical concepts such as geometric figures, fractions, and word sums. Learners are more able to invent solutions than being taught how to find solutions to mathematics activities ( $\mathrm{D}^{\prime}$ Ambrosio, 2009). Again,_ethnomathematics is appropriate to this paper as it affirms the marginalised knowledge that learners bring to school. Learners bring a huge wealth of knowledge which is rich in understanding mathematical content areas. More often than not this knowledge that learners have is sidelined in the teaching of mathematics word problems. Ethnomathematics as the conceptual framework can be used to enhance the teaching and learning of mathematical 
concepts in cultural and social contexts. Cultural and social contexts also embrace the playing of kgati and many other indigenous games.

\section{Methodology and Design}

In this qualitative case study, participatory action research (PAR) methodology was used as a tool to respond to the question: To what extent can learners use knowledge of indigenous game kgati to enhance the learning of mathematics words problems? PAR supports the research question in the sense that PAR encourages collaboration and sharing of ideas among learners in learning word problems. PAR, as an approach, mends social injustice between researchers and research participants, that is, it frees every participant to take ownership in the learning of mathematics word problems (Hertz-Lazarowitz, Zelnike \& Azaiza, 2010). Moreover, PAR as a methodology aligns very well with CCW as they both enable active participation from the marginalised groups. De Palma (2010) argues that PAR is an approach that unites learners from different cultural backgrounds and beliefs so that they consider mathematics word problems and think critically to interpret and solve them.

The researchers worked with a team of Grade 4 learners at a school located in the rural area of QwaQwa, in the Thabo Mofutsanyana District in the Free State Province, South Africa. The school was chosen because of its geographical position, in a deep rural village where indigenous games are played as part of extra-mural activities. The whole Grade 4 class of 35 learners volunteered to be part of this research study as most of them had not performed well in mathematics word sums in previous grades. Most of the learners view mathematics as a 'dull, boring subject' to learn, and as having little application to the outside world (Weldeana, 2015). As such, they were very excited to hear indigenous games that they know very-well would be used to teach mathematics word problems. The rest of the team that volunteered to participate in the study were the head of department for mathematics, two Grade 4 mathematics teachers, one life skills teacher, one district official from the Department of Basic Education (DBE), and three members of the local royal family. The Free State Department of Education and the school principal gave permission for this research project to commence, and parents signed consent forms on behalf of the learners to take part in the research project.

\subsection{Data Collection and Analysis}

In collecting data for the study, the research team used the moves of kgati to teach mathematics word problems by encouraging learners to make mathematical observations while playing this indigenous game, namely kgati (Figure 1). 


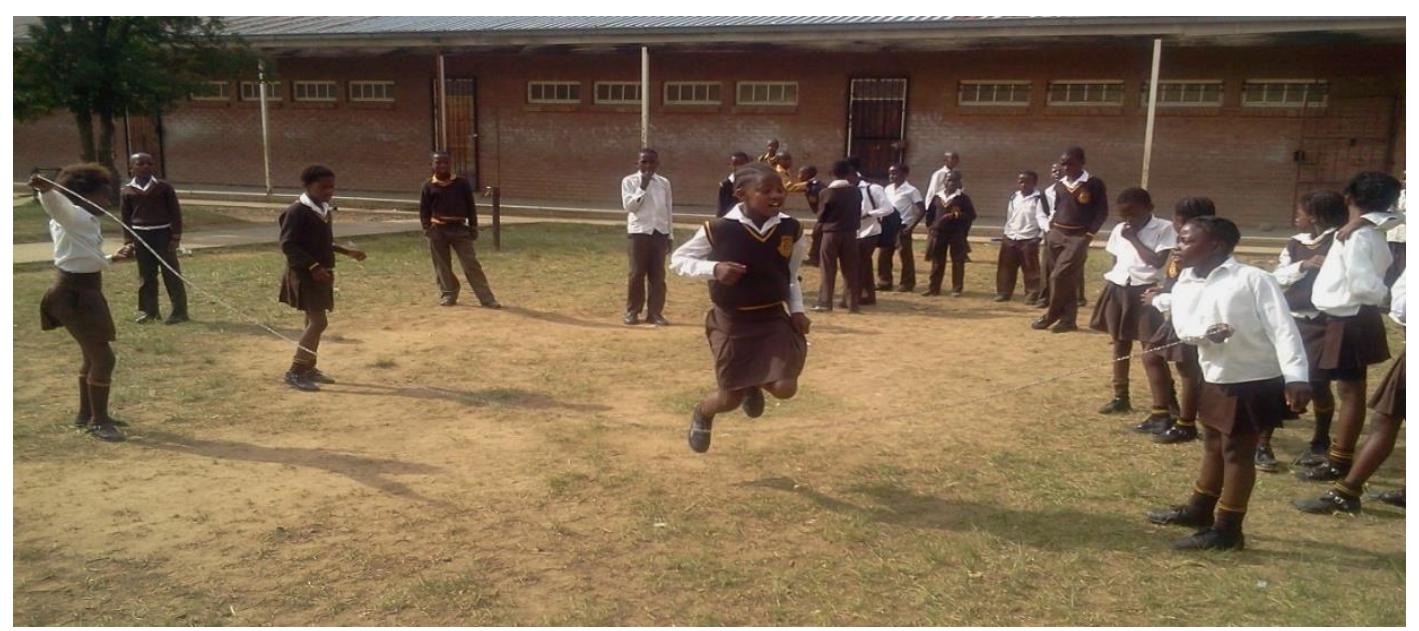

Figure 1: Kgati, a rope-jumping game

Figure 1 shows learners playing kgati, an indigenous game, while others observe its moves. According to Moloi (2015), learners can learn multiple realities from playing indigenous games. For the first stage of the lesson, the focus was to observe the moves of kgati and determine which geometric shapes were being formulated with the aim of interpreting, converting and integrating them into mathematics word problems. The moves of kgati refer to the way the rope changes shape when it moves, for example, when it swings down for the first time and touches the ground to form a loop that faces upwards, and when it swings up for the first time and weaves in the air to form another loop facing downwards.

The second stage of the lesson was about discussions and analysis of the observations. Critical discourse analysis was used to analyse what was observed, and to identify power balances (discursive practice) and social inclusion (social practice), especially where some learners were given a platform to demontrate the moves of kgati, while teachers, other learners and the rest of team members observed the moves of kgati.

Two groups selected from the research team, namely Group A and Group B, identified mathematics shapes from the moves of kgati. Each group was represented by two learners, one as the reporter and the other one as the coordinator. The task given to these groups was to observe a game and identify which kgati moves were identical to geometric shapes during a first swing, a second swing, as well as a third swing of the game. Group A volunteered to present and reflect on the first swing, Group B on the second swing, and a parent volunteered to reflect on the third swing. The groups observed the second movement of the rope, when it weaved in the air for the first time and formed a loop facing downwards

The last stage of the lesson was guided by a worksheet to show how the loop facing up and the loop facing down, which together form a full circle, could be converted and interpreted into geometric and numeric patterns to make sense of the learning of mathematics word problems for learners in elementary grades. 


\section{Worksheet}

This part of the lesson was presented by Mr Dintwe (not his real name) (the mathematics subject advisor) in the form of a table on behalf of the team. The presentations were made as follows:

Our table below presents four columns, of which the first column is used to represent the number of swings made by kgati (the skipping rope) (e.g., 1 representing one swing). In the second column, geometric patterns (e.g., $\stackrel{\mathrm{O}=}{\mathrm{v}}$ ) are presented, indicating the type of shapes created from observing the moves of kgati. The third column presents the number patterns (e.g., 1=1/2 + 1/2) formulated from observing geometric patterns in the second column. In the last column, word problems are created (e.g., one full swing is a half loop of the rope facing upwards, plus a half loop of the rope facing downwards). From observing the number of swings made by the rope in the first column, geometric patterns have been formulated in the second column and numeric patterns in the third column.

Table 1: Techniques of presenting $\mathrm{kgati}$ moves as a way to enhance learning of word problems

\begin{tabular}{|l|l|l|l|}
\hline $\begin{array}{l}\text { No. } \\
\text { full } \\
\text { swings }\end{array}$ & $\begin{array}{l}\text { Geometric } \\
\text { pattern }\end{array}$ & Numeric pattern & Mathematical word problem created \\
\hline 1 & $\begin{array}{c}\cap= \\
\cup\end{array}$ & $1=1 / 2+1 / 2$ & $\begin{array}{l}\text { One full swing is half a loop of the } \\
\text { rope facing upwards plus half a loop } \\
\text { of the rope facing downwards. }\end{array}$ \\
\hline 2 & & & \\
\hline 3 & & & \\
\hline
\end{tabular}

The table presented by Mr Dintwe on behalf of the team was intended to show whether learners would be able to convert geometric patterns (patterns presented in the form of shapes) and numeric patterns (patterns presented in the form of numbers) into mathematics word problems and interpret them. Another objective was to show the interdependent nature of columns in the table (how columns depend on each other). For this reason, learners were given a platform to complete the table. Morwesi and Thabo volunteered to complete the table. Morwesi started to complete the first part, where there were two full swings, while Thabo completed the second part where the number of swings given was three.Their responses were as follows: 
Table 2: Morwesi's response

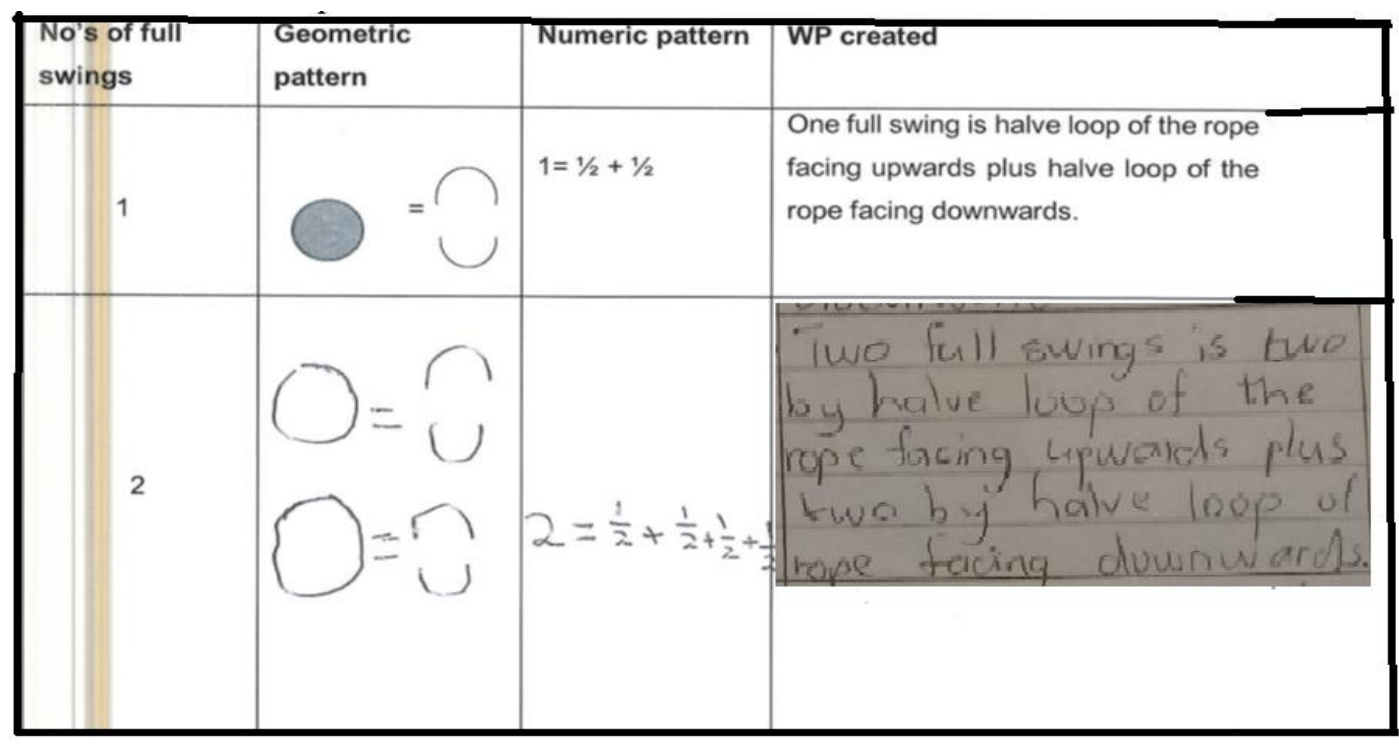

Table 2 shows the voluntary response of Morwesi. When learners were given a platform to complete the table, Morwesi volunteered to complete the first part, involving two swings. She attempted to determine the geometric pattern and numeric pattern from the number of swings given in the first column so as to create mathematics word problems. She first attempted to determine the geometric pattern in the second column, then she noted the number of swings in the first column( two swings), and the example. From the example, she learnt that one full swing was equal to one full circle, which equated to two half circles. Then, from this example, she reached the conclusion that two full swings would be determined by drawing two full circles, of which one could be equated to two half circles (one facing up and one facing down).

Her second attempt was to determine the numeric pattern. In determining the numeric pattern, she observed from the geometric pattern that two shapes had been formed from the number of swings in the first column, and each was equated to two halves. Then she drew and added two cirlces together, of which each equated to two halves. In her last attempt, she looked at the numeric pattern and found that the best way to create a word problem was to convert numeric patterns into mathematics word problems. Therefore, the number 2 was converted or written in word form, as two full swings, and equated to four halves in words. Nabie (2015) confirms that mathematics concepts are rooted in indigenous games. 
Table 3: Thabo's response

\begin{tabular}{|l|l|l|l|}
$\begin{array}{l}\text { No's of full } \\
\text { swings }\end{array}$ & $\begin{array}{l}\text { Geometric } \\
\text { pattern }\end{array}$ & Numeric pattern & WP created \\
\hline 1 & & $\begin{array}{l}\text { One full swing is halve loop of the rope } \\
\text { facing upwards plus halve loop of the } \\
\text { rope facing downwards. }\end{array}$ \\
\hline 3 & $1=\frac{1}{2}+\frac{1}{2}+\frac{1}{2}+1$ & Three full \\
\hline
\end{tabular}

Table 3 shows the responses made voluntarily by Thabo. When learners were given a platform to complete the table, Thabo volunteered to complete the first part where the given number of swings was three. He attempted to determine the geometric pattern and numeric pattern from the number of swings that was given in the first column so as to ultimately create a mathematics word problem. In his first attempt to determine the geometric pattern in the second column, he observed the number of swings in the first column (three swings), and the example. From the example, he learnt that one full swing was equal to one full circle, which equated to two half circles. Then, from this example, he drew the conclusion that three full swings would be determined by drawing three full circles, of which one could be equated to two half circles (one facing up and one facing down).

His second attempt was to determine the numeric pattern. In determining the numeric pattern, he observed from the geometric pattern that three shapes had been formed from the number of swings in the first column. Then he equated one full swing to two halves in each case in order to have three full swings, of which each one was equated to two halves. In his last attempt, he considered the numeric pattern and found that the best way to create a mathematics word problem was to convert or write the numeric pattern into mathematics word problem form. So, the number 3 was converted or written in word form as two full swings and equated to four halves in words. So, the number 3 was converted or written in word form as three full swings equated to six halves, also written in words. Moloi (2014) highlights that mathematics problem-solving, like all other forms of knowledge, is rooted in indigenous games and located within cultural contexts. 


\subsection{Lesson Reflections}

The mathematics teacher facilitated the discussions during the reflections phase. The focus was on to what extent learners used knowledge of indigenous games to enhance the learning of mathematics words problems. If not, the teachers and other research participants are able to clarify misconceptions that might arise. Learners from Group A and Group B shared their experiences and lessons learned with other groups. It was important to do the reflection so that learners gained different perspectives in understanding word problems. Also, they had an opportunity to ask questions and gain a deeper understanding of mathematics word problems using the moves of kgati.

Thus, this is in line with PAR principles, which suggest that opportunities need to be created for learners to share their expertise and make decisions together. Once again, this action allows learners to have ownership of the mathematical content presented.

\section{First swing}

The group observed the first movement of the rope when it touched the ground to form a loop facing upwards. During the observation time and identification time, Morwesi (not a real name) (a learner who served as group coordinator and reporter) articulated the following on behalf of Group A:

Ka tlwaelo kgati e bapallwa for boithabiso, re thabela ho ithuta hore e bapala karolo ya bohlokwa dipalong [normally, the kgati game is played for enjoyment; now we learn that the game can be used to learn mathematics]. Jwale, hare tadima se etsuwang ke kgati mona re hlokomela hore ha sedikadikwe se ka tlase se ama lefasthe, re ipopela setshwantsho sa thapo ya sedikadikwe se shebileng hodimo. [Now, when we observe the moves of kgati, we discover that, whenever a first swing is done, the rope touches the ground and forms a loop facing up]. Ho ya ka rona sedikadikwe sena ka dipalo ke sekele e hafo e shebileng hodimo [In our understanding, in mathematics, the loop facing up is called a half circle facing up].

The word, 'normally' denotes that it was a norm or a habit of the group that learners played kgati for enjoyment, but this changed when the group discovererd that mathematics could also be learnt through the moves of kgati.

This realisation is affirmed by Knight (2003), who claims that there are multiple ways of learning mathematics, particularly mathematics word problems. The use of the pronoun 'we' in the passage suggests, furthermore, balanced power relations amongst the members of the team because a learner was given a platform to report and coordinate the team's research proceedings, some team members observed and identified the moves that resembled mathematics shapes while others demonstrated the moves of kgati. This venture helped them because the team realised that, when the rope swings down and touches the gound, a shape in the form of a loop facing upwards was formed; then they realised that, from that shape, a geometric shape was formed (i.e. semicircle facing upwards). 
In summary, learners learn that when the rope swings up for the first time and touches the ground, a $\cup$ shape is formed. So, mathematically, this $\cup$ shape is said to be a semi-circle facing upwards. This shape forms part of a full cirlce. The team learnt that mathematical shapes can be learnt from a cultural environment, such as the moves of kgati. Thus learners were able to solve problems in context involving common fractions and the addition of fractions with the same denominator to obtain a whole number.

\section{Second swing}

During the observation and identification time, Morena (not a real name) (a learner who served as a group coordinator and reporter) articulated the following on behalf of Group B:

Ka kutwisiso ya rona sedikadikwe sena se bopa mofuta wa serkele of shebileng fatshe [In our understanding, this loop forms a kind of a circle facing down]. Mofuta ona wa serkele ka dipalo re utwisisa hore ke halofo ya serkele e shebileng fatshe [We learn in mathematics that this type of loop facing down is a half circle facing down].

The word 'our' from the above passage denotes that the research activity was owned by the entire team. This was clear when the research activities were shared fairly amongst the members of the team. For example, three learners were given opportunities to demonstrate how the game was played, others observed and identified mathematical shapes in the moves of kgati, while one learner coordinated and reported the moves on behalf of the entire team. This coorperative work was in line with PAR. According to Vongai and Elaosi(2017), one of the principles of PAR is to allow people to work together in order to attain common goals. One of the goals pursued by this study was to see the team exploring what mathematical shapes could be formed by the moves of kgati. This was done because the team noticed that, whenever the rope weaved up in the air, it formed a loop facing down, and from that loop, they deduced that a semicircle facing downwards was formed.

Furthermore, the word 'we' indicates that social inclusion was practised fairly in the study and amongst the team members. This practice was observed during the research proceedings when all participants were given platforms to take part in the lesson. They had been selected from different walks of life with the intention to share the indigenous knowledge they possessed to make this study a success.

In summary, learners learn that when the rope swings up for the second time, a semicircle facing down $\cap$ is formed. The moves of kgati enable learners to fulfill Grade 4 mathematics curriculum content specifications, that is to recognise, visualise and name 2-D shapes in real-life contexts.

\section{Third swing}

The groups observed what type of shape was formed when the first swing and second swing were pooled. During the observation and identification time, 
Ntate Mokoena (a parent who served as a group coordinator and reporter) articulated the following on behalf of the entire team:

Re hlokomela hore ha re kopanya sedikadikwe sa pele se shebileng hodimo mmoho le se shebileng fatshe se bopa serkele e felletseng [We observed that, when we put or combine the loop facing up together with the loop facing down, the two loops form a full circle].

The phrase "sedikadikwe sa pele se shebileng hodimo [loop facing up]" demonstrates that familial and linguist capitals are very rich in explaining mathematical concepts to learners. The way they talk shows that there are many mathematical concepts embedded within their home language.

Again, the word 'we' denotes that it was the efforts of the whole team that determined that, when they combined the semicircle facing up $\cup$ with the semicircle facing down $\cap$, a full circle $\bigcirc$ was formed. This type of collaborative effort by the team was similar to that of the teams involved in analysing the other two moves, as described above. Therefore, we can conclude that the entire team learnt that a full circle is formed when the loop facing up is connected with the loop facing down, as can be seen in the indigenous game of kgati. In addition, the team realised that their linguistic capital is very rich in describing mathematical concepts and this brings a deeper undestanding of word problems.

\section{Findings}

The findings of this study reveal that learners were able to identify mathematical shapes such as circles and semi-circles from the moves of kgati, and were able to interpret, convert and link the shapes to word problems. Learners were able to use the indigeneous knowledge gained by playing and observing moves of kgati to interpret and understand mathematics word problems relating to the geometrical shapes that they observed from the kgati moves. The familial capital (for instance, community history of interactions through sports activities) and linguistic capital (such as Sesotho and Setswana languages learners learnt from home to describe geometric shapes illustrated by kgati) possessed by the team members assisted them to extrapolate mathematical concepts embedded within the movement of kgati.

The study highligted the interdependent nature of the columns in Table 1 as of vital importance. Because the columns were independent, learners could count the number of swings given in the first column to determine or draw the number of geometric shapes or the shapes needed in the second column. By determining these numeric patterns, participants had to observe geometric shapes formed from the second column count and convert them into the numeric patterns (patterns in the form of numbers). Lastly, by creating mathematics word problems, they had to reflect back on the numeric patterns they had formulated in the third column, and write mathematical sentences or statements linking to those numbers. 


\section{Study Limitations}

The study noted some limitations. Firstly, the use of kgati gave learners an understanding of circles and semi-circles but not of other geometrical figures. Secondly, the different swings of kgati yield few specific fractions $\left(\frac{1}{2}\right)$ and not others like $\left(\frac{1}{4}\right),\left(\frac{5}{8}\right)$. Thirdly, adding fractions from different swings only gave learners the opportunty to add fractions with same demoninator.

\section{Conclusion}

In responding to the research question regarding the extent to which learners can use knowledge of the kgati game to enhance the learning of mathematics words problems, the study contends that, while indigenous knowledge and games were being neglected, or less used, learners explored the value of the kgati game as dynamic. This was seen during the observation, identification and interpretation when the learners formulated mathematical shapes from the moves of kgati through discussions of swings, namely, a first swing, a second swing and a third swing. In the first swing, a geometric shape of a semicircle facing up was formed; in the second swing, a geometric shape of a semicircle facing down was formed; then, in the third swing, two semicircles (the one facing up and the one facing down) were joined together to form a full circle. The linguistic capital that learners possess (indigenous languages and Sesotho) embraces mathematical concepts. For instance,"ha sedikadikwe se ka tlase se ama lefasthe, re ipopela setshwantsho sa thapo ya sedikadikwe se shebileng hodimo", mathematically they visualise a semicircle facing upwards. Actually, through their indigenous languages, learners constructed word problems of which they were also able to figure out the graphical representations. Furthermore, these graphical reprensations could be described numerically.

Finally, the study noted part of the knowledge-conveyed-area of the curriculum. The knowledge-conveyed-area refers to the part of school-based assessment whereby learners are given platforms to introduce, convey and link indigenous knowledge, skills and games they may be aware of with mathematics in free learning spaces. By doing so, the Department of Basic Education (DBE, 2011) declares they will see the beauty of mathematics and learn school mathematics at grade 4 level better, and with understanding. Learners are able to realise that the playing of kgati improves their understanding and appreciation of patterns as well as the beauty of mathematics in natural and cultural forms. It is noted that ethnomathematics serves as a transformative played-based teaching strategy that enhances the learning of word problems. Ethnomathematics as the tranformative play-based teaching strategy integrates the play of kgati into school mathematics that provides learners with a deep understanding of word problems. Also, it gives learners opportunities to make sense of word problems by using their background and personal experiences. It is recommended that indigenous games be a critical element element in the process of learning mathematics word problems. Shizha and Emeagwali (2016) acknowledge them as imperative because the knowledge used is original and initiated by colonised African ancestors as the way of knowing and did not necessarily begin with the coming of colonial Western systems. 
* Footnote: Kgati (A rope-jumping game or skipping rope game): This kind of indigenous game is played on open ground with an even, hard surface. The skipping rope swing freely and the players should be able to jump over it with ease. Two players are chosen to swing the rope. They take up position opposite each other. The two players swing the rope to form a loop and swing it low across the surface of the ground. The other player(s) jump over the rope when it reaches the lowest point (Department of Sports and Recreation, 2006).

\section{References}

Arenas, A., Reyes, I., \& Wyman, L. (2017). When indigenous and modern education collide. In J. Zajda \& K. Freeman (Eds.), Race, ethnicity and gender in education. Cross-cultural understandings. Tucson, AZ: University of Arizona. doi:10.1007/978-1-4020-9739-3_4

Bishop, A. J. (1988). Mathematics education and its cultural context. Educational Studies in Mathematics, Mathematics Education and Culture, 19(2), 79-191.

Chapman, O. (2006). Classroom practices for context of mathematics word problems. Educational Studies in Mathematics, 62(2), 211-230. https://doi.org/10.1007/s10649-006-7834-1

Chimuka, A. (2017). The effect of integration of Geogebra software in the teaching of circle geometry on Grade 11 students' achievement [Master's thesis]. University of South Africa.

Conrad, J. (2019). The big history project and colonizing knowledges in world history $\begin{array}{llll}\text { curriculum. Journal of } \quad \text { Curriculum } & \text { Studies, 51(1), }\end{array}$ doi:10.1080/00220272.2018.1493143

Cooper, C. R., Gonzalez, E., \& Wilson, A. R. (2014). Identities, cultures \& schooling: How students navigate racial-ethnic, indigenous immigrant, social class \& gender identities on their pathways through school. In K.C. Mclean \& M. Syed (Eds.). The Oxford handbook of identity development. Oxford University Press. doi:10.1093/oxfordhb/9780199936564.013.018

D'Ambrosio, U. (2009). Mathematical modeling: Cognitive, pedagogical, historical and political dimensions. Mathematical Modelling and Application, 1(1), 89-98.

Davis, J. (2018). Redefining black students' success and high achievement in mathematics education: Toward a liberatory paradigm. Journal of Urban Mathematics Education, 11(1-2), 69-77.

De Palma, R. (2010). Socially just research for social justice: Negotiating consent and safety in a participatory action research project. Facaltade de Clencias da Education, University of Vigo, Ourense, Spain. International Journal of Research \& Method in Education, 33(3), 215-227. doi:10.1080/1743727X.2010.511713

Department of Basic Education. (2011). Mathematics: Curriculum and assessment policy statement Grades 4-6. Pretoria: Department of Basic Education. www.education.gov.za > Curriculum > Curriculum Assessment.

Department of Basic Education. (2014). Annual national assessment. Curriculum and assessment policy. Pretoria, SA: Department of Basic Education www.education.gov.za > Curriculum > Annual National.

Department of Sport and Recreation. (2017). Indigenous games general and code specific rules. Pretoria, SA: Department of Sport and Recreation.

Dziva, D., Mpofu, V., \& Kusure, L. P. (2011). Teachers' conception of indigenous knowledge in science curriculum in the context of Mberengwa District, Zimbabwe. African Journal of Education and Technology, 1(3), 88-102. 
Ernest, P. (2010). The social outcomes of learning mathematics: Standard, unintended or visionary. International Journal of Education in Mathematics, Science and Technology, 3(3), 187-192. doi:10.18404/IJEMST.29471

Fang, Y. (2010). The cultural pedagogy of errors: Teacher Wang's homework practice in teaching geometry proofs. Journal of Curriculum Studies, 42(5), 597-619. https://doi.org/10.1080/00220271003773901

Filmer, D. A. (2015). Berlusconi's language in the British press: Translation, ideology and national image in news discourse across Italian/English Linguacultures [PhD dissertation]. Durham University. http://etheses.dur.ac.uk/11049/

Food and Agriculture Organization of the United Nations (FAO). (2015). Mapping the vulnerability of mountain peoples to insecurity. Rome: FAO. http://www.fao.org/3/a-i5175e.pdf

Gail, E. F. (2002). Introduction: Cultural aspects of mathematics education. Journal of Intercultural Studies, 23(2), 109-118. doi:10.1080/07256860220151032

Hertz-Lazarowitz, R., Zelniker, T., \& Azaiza, F. (2010). Theoretical framework for cooperative participatory action. Research (CPAR) in a multicultural campus: The social drama model. Faculty of Education, University of Haifa, Israel. Intercultural Education, 21(3), 269-279. doi:10.1080/14675981003760457.

Hunter, R., \& Hunter, J. (2018). Opening the space for all students to engage in mathematical practices within collaborative inquiry and argumentation. In R. Hunter, M. Civil, B. Herbel-Eisenmann, N. Planas \& D. Wagner (Eds.), Mathematical discourse that breaks barriers and creates space for marginalized learners (pp. 1-21). Brill Sense. https://doi.org/10.1163/9789463512121_001

Igboin, B. O. (2011). Colonialism and African cultural values. African Journal of History and Culture, 3(6), 96-103. https://doi.org/10.5897/AJHC.9000008

Imray, P., \& Hinchcliffe, V. (2013). Curricula for teaching children and young people with severe or profound and multiple learning difficulties: Practical strategies for educational professionals. Routledge. https:// doi.org/10.4324/9781315883298

Januarie, V. (2019). The educational achievement routes of first generation students in a rural town [Master's thesis]. Stellenbosch University.

Kavalo, Y. (2014). Exploration of indigenous knowledge practices of the relatives of mental health care users regarding management of mental disorders in Malawi [Master's thesis]. University of Fort Hare.

Kaya, H. O., \& Seleti, Y. N. (2013). African of indigenous knowledge systems and relevance of higher education in South Africa. The International Education Journal: Comparative Perspective, 12(1), 30-44. http:// files.eric.ed.gov/fulltext/ej1017665.pdf

Khupe, C., \& Keane, M. (2017). Towards an African education research methodology: Decolonising new knowledge. Educational Research for Social Change (ERSC), 6(1), 25-37. http://dx.doi.org/10.17159/2221-4070/2017/v6i1a3.

Knight, I. R. (2003). The games children play: The foundation for mathematical learning. Paris Division of Basis Education, UNESCO. https://unesdoc.unesco.org/ark:/48223/pf000132671

Lucero, A. (2010). Dora's program: A constructively marginalized paraeducator and her development biliteracy program. Anthropology \& Education Quarterly, 41(2), 126143. doi:10.1111/j.1548-1492.2010.01074.x

Lynn, M. (2004). Inserting the "race" into critical pedagogy: An analysis of race-based espistemologies. Educational Philosophy of Theory, 36(2), 153-164. doi:10.1111/j.1469-5812.2004.00058.x 
MacDonald, C. (2012). Understanding participatory action research: A qualitative research. Methodology Option. Canadian Journal of Action Research, 3(2), 34-50. https://www.researchgate.net/publication/274063607

Maferetlhane, O. I. (2012). The role of indigenous knowledge in disaster risk reduction. A critical analysis [Master's dissertation]. North-West University.

Masote, S. E. (2016). Teachers' understanding and implementation of values education in the foundation phase [PhD thesis]. University of Pretoria. http://hdl.handle.net/2263/60957

Matusov, E., \& Marjanovic-Shane, A. (2017). Promoting students' ownership of their own education through critical dialogue and democratic selfgovernance. Dialogic Pedagogy: An International Online Journal,5, 1-29. https://doi.org/10.5195/dpj.2017.199

Moloi, T. J. (2013). An analysis of challenges in the teaching of problem solving in Grade 10 mathematics. TD The Journal for Transdisciplinary Research in Southern Africa, 9(3), 480-492. https://doi.org/10.4102/td.v9i3.192

Moloi, T. J. (2015). Using indigenous games to teach problem-solving in mathematics in rural learning ecologies. Journal of Higher Education in Africa (JHEA), 13(1\&2), 2132. http://www.jstor.org/stable/jhigheducafri.13.1-2.21

Moro, M. (2020). Conversations with the unconscious: Learn to get in touch with the deepest part of yourself and pull your own strings. Blu Editore.

Moxham, L., Dwyer, T., Happell, B., Rei-Searl, K., Kahl, J., Morris, J., \& Wheatland, N. (2010). Recognising our role: Improved confidence of general nurses providing care to young people with a mental illness in a rural paediatric unit. Journal of Clinical Nursing, 19, 1434-1442. doi:10.1111/j.1365-2702.2009.02993.x

Mukhopadhyay, S. (2013). The mathematical practices of those without power. In M. Berger, K. Brodie, V. Frith, \& K. le Roux (Eds.), Proceedings of the Seventh International Mathematics Education and Society Conference, Cape Town, SA.

Nabie, M. J. (2015). Where cultural games count: The voices of primary classroom teachers. International Journal of Education in Mathematics, Science and Technology, 3(3), 219-229.

Nkopodi, N., \& Mosimege, M. (2009). Incorporating the indigenous game of Morabaraba in the learning of mathematics. South African Journal of Education, EASA, 29, 377392. doi:10.15700/saje.v29n3a273

Odora Hoppers, C. A. (Ed.). (2002). Indigenous knowledge and the integration of knowledge systems: Towards a philosophy of articulation. New Africa Books.

Osibodu, O. O. (2020). Embodying ubuntu, invoking Sankofa, and disrupting with fela: A coexploration of social issues and critical mathematics education with sub-Saharan African youth [PhD thesis]. Michigan State University.

Riffel, A. D. (2020). Social and cultural relevance of aspects of indigenous knowledge systems (IKS), meteorological literacy and meteorological science conception [PhD thesis]. University of the Western Cape. http://hdl.handle.net/11394/7258

Rosa, M., \& Orey, D. C. (2016). Humanizing mathematics through ethnomodelling. Journal of Humanistic Mathematics, 6(2), 3-22. doi:10.5642/jhummath.201602.03

Rubel, L. H. (2017). Equity-directed instructional practices: Beyond the dominant perspective. Journal of Urban Mathematics Education, 10(2), 66-105. doi:10.21423/jume-v10i2a324

Sepeng, P. (2015). Discussions, argumentations and realistic considerations in mathematics word problem solving. Proceedings of the 21st Annual National Congress of the Association for Mathematics Education of South Africa. South Africa: University of Limpopo. 
Shizha, E., \& Emeagwali, G. (Eds.). (2016). African indigenous knowledge and the sciences. Journey into the past and present. Series Anti-Colonial Educational Perspectives for Transformative Change. Brill Sense. https://doi.org/10.1007/97894-6300-515-9

Shonhai, V. F. (2016). Analysis South African indigenous knowledge policy and its alignment to government's attempts to promote indigenous vegetables [PhD thesis]. University of KwaZulu-Natal, Durban. http://hdl.handle.net/10413/14927

Ukala, C. C., \& Agabi, O. G. (2017). Linking early childhood education with indigenous education using gamification: The case of maintaining cultural value and identity. Journal of International Education Research, 13(1), 17-26. https:// doi.org/10.19030/jier.v13i1.9960

Van Dijk, T. A. (2004). Discourse, knowledge and ideology: Reformulating old questions and proposing some new solutions. In M. Pütz, J. Neff, \& T. A. van Dijk (Eds.), Communicating ideologies. Multidisciplinary perspectives on language. Discourse and social practice (pp. 5-38). Frankfurt, Germany: Peter Lang.

Van Oers, B. (2010). Emergent mathematical thinking in the context of play. Education Studies in Mathematics, 74, 23-37. https://doi.org/10.1007/s10649-009-9225-x

Vega, J. A. R. (2014). From Verguenza to Echale Ganas: Counter storytelling narratives of Latino teenage boys naming oppression and unpacking community cultural wealth [Doctoral dissertation]. University of North Carolina Greensboro. https://libres.uncg.edu/ir/uncg/f/RiosVega_uncg_0154D_11306.pdf

Vongai, M., \& Elaosi, V. (2017). Indigenous knowledge and nature of science interface: Content considerations for science, technology, engineering, and mathematics education. World Academy Science, Engineering and Technology International Journal of Educational and Pedagogical Sciences, 11(5), 1320-1328. doi:10.5281/zenodo.1131663

Weldeana, H. N. (2016). Ethnomathematics in Ethiopia: Futile or fertile for mathematics education? Momona Ethiopian Journal of Science (MEJS), 8(2), 146-167. doi:10.4314/mejs.v8i2.4

Williams, J. (2017). Embedding indigenous content in Australian physical education perceived obstacles by health and physical education teachers. Learning Communities, Special Issue, 30th ACHPER International Conference, 21, 124-136. https://doi.org/10.18793/LCJ2017.21.10

Williams, T. (2019). A review of African thinkers on neocolonialism, cultural imperialism and class struggle in Africa: Toward the redemption of the African consciousness. http://dx.doi.org/10.2139/ssrn.3748907

Wright, B. L. (2018). The brilliance of Black boys: Cultivating school success in the early grades. Teachers College Press.

Xenofontos, C., \& Papadopoulos, C. E. (2015). Opportunities of learning through the history of mathematics. Department of Education, University of Nicosia: Cyprus. https://www.researchgate.net/publication/280100567

Young, F., \& Murray, G. (2017). Designing for serious play. In S. Lynch, D. Pike \& C. à Beckett (Eds.), Multidisciplinary perspectives on play from birth and beyond. (pp. 163-179). Singapore: Springer. https://doi.org/10.1007/978-981-10-2643$0 \_10$

Yosso, T. J. (2005). Whose culture has capital? A critical race theory discussion of community cultural wealth. Race, Ethnicity and Education, 8(1), 69-91. doi:10.1080/1361332052000341006 


\section{Appendix}

\section{Ethical Clearance}

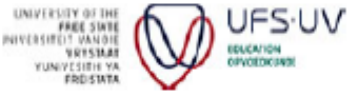

Faculty of Education

14-Dec-2017

Dear Mr Khanyae Sibaya

Ethics Clearance: A context-based strategy for teaching and learning of word problems for Afromontane learners

Principal Investigator: Mr Khanyae Sibaya

Department: School of Education Studies (Bloemfontein Campus)

APPLICATION APPROVED

With reference to you application for ethical clearance with the Faculty of Education, I am pleased to inform you on behalf of the Ethics Board of the faculty that you have been granted ethical clearance for your research.

Your ethical clearance number, to be used in all correspondence is: UFS-HSD 2016/1290

This ethical clearance number is valid for research conducted for one year from issuance. Should you require more time to complete this research, please apply for an extension.

We request that any changes that may take place during the course of your research project be submitted to the ethics office to ensure we are kept up to date with your progress and any ethical implications that may arise

Thank you for submitting this proposal for ethical clearance and we wish you every success with your research.

Yours faithfully

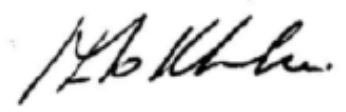

Prof. MM Mokhele

Chairperson: Ethics Committee

Education Ethics Committee

Office of the Dean: Education

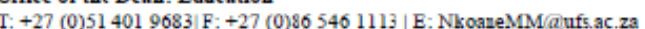

Winkie Direko Building | P.O. Box/Posbus 339| Bloemfontein 9300 | South Africa

www.ufs ac.za 